\title{
Physiotherapy UTILISATION BY SPORTS PHYSICIANS FOR MUSCULOSKELETAL INJURIES in SElected Elite Sports in NigERIA.
}

\begin{abstract}
In Nigeria, the majority of injured athletes seen in sports physiotherapy units are referred by sports physicians. The extent to which a physician utilises the services of physiotherapy in sport depends largely on the level of awareness or knowledge of physiotherapy services that such physicians have. This survey evaluated the degree of utilisation of physiotherapy services for the treatment of injuries during preparation for multi-sports events by sports physicians in selected elite

USHOTANEFE U', MBAJIOGU FE', SANYA AO $^{2}$

'Department of Rehabilitation and Anatomy, Faculty of Medicine, University of Zimbabwe

2Department of Physiotherapy, College of Medicine,

University of Isaban, Nigeria sporting events in Nigeria.

One hundred and twenty-eight athletes, coaches, sports administrators, scientists, medical doctors and physiotherapists located at four different camping sites, were sampled. The responses between different professional groups on the non-utilisation of physiotherapy services by sports physicians during preparation for multi-sport events, was not significant. However, Nigerian professionals who were surveyed, accepted the hypothesis that sports physicians did not utilize physiotherapy services for the management of musculoskeletal injuries during training and pre-games preparation in selected elite sports in Nigeria.

This retrospective study of the actual referral records at the clinic of the sports medicine centre revealed that $20(91 \%)$ different types of musculoskeletal injuries sustained by volley ball players were referred for physiotherapy. Nine (56.3\%) injuries sustained by basketball players, $62(87.3 \%)$ by track and field athletes, and $6(74 \%)$ by football players were referred for physiotherapy between 1992 and 1995. The majority of the injuries sustained were ligamentous sprain and muscular strain with joints of the lower limbs and the back mostly affected.
\end{abstract}

\section{KEYWORDS: UTILISATION, ELITESPORTS, PHYSIOTHERAPY, SPORTS PHYSICIANS.}

\section{INTRODUCIION}

Performance of sportsmen and women in their chosen sports depends on the support received from members of the training crew. This crew ensures that the state of preparedness, well being and the physical fitness of the athletes is optimal. In developed countries, membership of such a crew usually consists of the coach or/and the trainer, sport physician, the physiotherapist, the exercise physiologist and team managers. Watson (1993) expressed the opinion that for an athlete to be successful at the highest level of sport, commitment to a systematic and demanding programme of training and competition extending over a protracted period of several months or years, is a requirement. Such a training programme could be disrupted if the injuries sustained are not adequately managed. The management of these injuries requires a team effort; the physiotherapist being a member of such a team.

In Nigeria, the majority of injured athletes treated in sports physiotherapy units are referred by sports physicians, while in other countries, physiotherapy is a first contact profession though they also frequently depend on referrals from doctors. The extent to which physicians utilise the services of physiotherapists in sport depends largely on the level of awareness or knowledge of these physicians of the available physiotherapy services (Allman, 1974). Thus physicians' knowledge of the role played by physiotherapists working with athletes influence the number of referred cases for physiotherapy.

Also implicated in the extensive use of physiotherapy services are the physiotherapists themselves. Some physiotherapists are not aware of their possible roles in the treatment of sports injuries (Sperryn, 1976).

In our experience of sport in Nigeria, it has become evident the list of professionals working with sportsmen and women is reduced at the whim and caprice of those making the decisions on treatment for various reasons. Ignorance and budgeting constraints (due to lack of funds) often affect this decision. The physiotherapist is a member of the crew who has to date been haphazardly utilised.

Many different injuries occur during sporting events. The type of injuries, causes and parts of the body that are commonly injured, in multi-sport events have been reported in previous epidemiological studies (Jull and Cupit, 1984; Ahuja and Ghosh, 1985; Sadat-Ali and Sankaran-Kutty, 1985; Watson, 1993; Hannay et al, 1993; Jelsma et al, 1997 a and b; Karlsson, 1998; and Fahlstrom et al, 1998).

CORRESPONDENCE: Useh Ushotanefe Department of Rehabilitation, Faculty of Medicine, University of Zimbabwe,

P. O. Box MP 167,

Mount Pleasant, Harare, Zimbabwe.

Tel: 263(4) 791631 Ext 175(w) 
There was a dearth of information and literature on injuries sustained during preparation for these multi-sport events. It was also observed that there was no study on physiotherapy utilisation during preparation for these games.

The aim of this study was to evaluate the degree of utilisation of physiotherapy services by sports physicians for the treatment of injuries during physical training and preparation for multi-sports events in Nigeria. We also attempted to investigate the common musculoskeletal injuries that were referred for physiotherapy, and recorded the sport that was responsible for the most referrals within a sports medicine facility.

\section{SUBJECTS AND METHODS}

One hundred and twenty-eight different sports professionals were included in our sample. The group consisted of physiotherapists, medical doctors, sports scientists, sports administrators, coaches and elite athletes who participated in the preparatory camp for the sixth All Africa Games.

The group was selected from the sixth All African Games (AAG) preparatory camps located in four different zones (Kaduna (Northern zone), Ibadan (Western zone), Bauchi (Central zone) and the Lagos zone in Nigeria.

\section{Inclusion Criteria:}

The participants were professionals from different parts of the country including some athletes from abroad who turned up for the preparatory camps. The professionals and athletes should have taken part in high level sports or should have been involved in preparations for events of the standard of the All Africa Games. This ensured adequate exposure and experience for the participants and therefore guaranteed accurate and unbiased responses to the questionnaire.

\section{Instrument:}

The instrument for data collection was a self-developed questionnaire, which was pre-tested (by the first author) to resolve any problems and ambiguities around the questionnaire. The questionnaire was divided into three sections: A, B and C. Section A was concerned with the personal and demographic data

Table 1. The responses of professionals and athletes to the hypothesis that sports physicians do not use physiotherapy services for the treatment of injuries during training for multi-sports events.

\begin{tabular}{|c|c|c|c|c|c|c|c|c|c|c|}
\hline \multirow{2}{*}{$\begin{array}{c}\text { Professional } \\
\text { groups }\end{array}$} & \multicolumn{8}{|c|}{ Response Options } & \multirow{2}{*}{\multicolumn{2}{|c|}{ Total }} \\
\hline & \multicolumn{2}{|c|}{ SA } & \multicolumn{2}{|c|}{ A } & \multicolumn{2}{|c|}{ D } & \multicolumn{2}{|c|}{$\mathrm{SD}$} & & \\
\hline & No. & $\%$ & No. & $\%$ & No. & $\%$ & No. & $\%$ & No. & $\%$ \\
\hline Sports scientists & 3 & 75 & 1 & 25 & 0 & 0 & 0 & 0 & 4 & 3 \\
\hline Medical doctors & 10 & 67 & 5 & 33 & $\overline{0}$ & 0 & 0 & 0 & 15 & 12 \\
\hline SADM & 3 & 20 & 12 & 80 & 0 & 0 & 0 & 0 & 15 & 12 \\
\hline Physiotherapists & 8 & 100 & 0 & 0 & 0 & 0 & 0 & 0 & 8 & 6 \\
\hline Coaches & 26 & 62 & 13 & 31 & 3 & 7.2 & 0 & 0 & 42 & 33 \\
\hline Athleles & 22 & 50 & 20 & 45 & 1 & 2.3 & 1 & 2.3 & 44 & 34 \\
\hline TOTAL & & & & & & & & & & \\
\hline OVERALL \% & 72 & 56 & 51 & 40 & 4 & 3 & 1 & 0.8 & 128 & 100 \\
\hline - Sports & $\overline{\text { minist }}$ & & & SD & & $\overline{n g} D$ & agree & & & \\
\hline - Strong & Agree & & & A & $-A$ & & & & & \\
\hline - Disaso & & & & No. & & nber & Sut & & & \\
\hline - Percer & & & & & & & & & & \\
\hline
\end{tabular}

Table 2. The degree of agreement and disagreement of responses by the professional groups.

\begin{tabular}{|l|l|l|}
\hline \multicolumn{1}{|c|}{ Professional groups } & SA+A & D+SD \\
\hline SS & $4(100)$ & 0 \\
\hline MD & $15(100)$ & 0 \\
\hline SADM & $15(100)$ & 0 \\
\hline Physios & $8(100)$ & 0 \\
\hline Coaches & $39(93)$ & $3(7.2)$ \\
\hline Athletes & $42(95)$ & $2(5)$ \\
\hline TOTAL & 123 & 5 \\
OVERALL \% & $(96)$ & {$[4]$} \\
\hline
\end{tabular}

$\begin{array}{llll}\text { SADM } & \text { - Sports Administrators } & \text { SA } & \text { - Strongly Agree } \\ \text { SS } & \text { - Sports Scientist } & \text { A } & \text { - Agree } \\ \text { MT } & \text { - Medical Team } & \text { D } & \text { - Disagree } \\ \text { SADM } & \text { - Sports Administrators } & \text { SD } & \text { - Strongly Disagree } \\ \text { PHYSIOS } & \text { - Physiotherapists } & \text { No } & \text { - Number of subjects }\end{array}$

Values in bracket are percentages

of each of the participants. Section B tested the participant's knowledge of the use of physiotherapy services by sport physicians in sports, and section $\mathrm{C}$ dealt with the actual utilisation of physiotherapy services in participants respective clinics/or medical centres/or sporting associations. The questionnaire was designed in a Likert model and scaled on a four-point scale. This enabled the respondents to indicate the extent of agreement or disagreement for every statement examined.

The data obtained from the questionnaire were augmented with the data from the retrospective examination of the records of injuries at the National Sports Medicine Centre, Lagos. This centre is located within the National sports complex and is used for the treatment of sports men and women when camping for national and international competitions.

All the questionnaires for the professionals were hand-delivered to them. This was done to ensure that the participants received them in good time and enabled the researchers to make appointments for the retrieval of the instrument. Individual coaches and all professionals were approached at the different camp locations and sporting associations. The questionnaires that were completed by the athletes were returned by their coaches. None of the coaches declined to take part. The researchers also met with the team doctors and physiotherapists during 
Table 3. The use of physiotherapy services for the treatment and rehabilitation of musculoskeletal injuries in the facilities of the professionals.

\begin{tabular}{|c|c|c|c|c|c|c|}
\hline \multirow{3}{*}{$\begin{array}{c}\text { Professional } \\
\text { groups }\end{array}$} & \multicolumn{6}{|c|}{ Response Options } \\
\hline & \multicolumn{2}{|c|}{ YES } & \multicolumn{2}{|c|}{ NO } & \multicolumn{2}{|c|}{ Total } \\
\hline & No. & $\%$ & No. & $\%$ & No. & $\%$ \\
\hline Sports scientists & 2 & $(50)$ & 2 & $(50)$ & 4 & (3) \\
\hline $\mathrm{p}^{*}$ & 0.62 & & & & & \\
\hline Medical Doctors & 9 & (79) & 6 & (21) & 15 & (12) \\
\hline$\overline{p^{*}}$ & 0.88 & & & & & \\
\hline Sports Administrators & 9 & (79) & 6 & (21) & 15 & $(12)$ \\
\hline $\mathrm{p}^{*}$ & 0.88 & & & & & \\
\hline Physiotherapists & 5 & (63) & 3 & (38) & 8 & (6) \\
\hline$p^{*}$ & 0.9626 & & & & & \\
\hline Coaches & 25 & (60) & 17 & (41) & 42 & (33) \\
\hline $\mathrm{p}^{*}$ & 0.87 & & & & & \\
\hline Athletes & 29 & (66) & 15 & (34) & 44 & (34) \\
\hline $\mathrm{p}^{*}$ & 0.06 & & & & & \\
\hline $\begin{array}{l}\text { TOTAL } \\
\text { OVERALL \% }\end{array}$ & 79 & $(62 \%)$ & 49 & $(38 \%)$ & 128 & $(100 \%)$ \\
\hline
\end{tabular}

No. - Number of professionals surveyed

$\% \quad$ - Values in bracket are percentages

$\mathrm{p}^{*} \quad$ - $\mathrm{p}$-value computed for the Chi-square Test

Table 4. Comparison of responses between the different professional groups.

\begin{tabular}{|l|l|l|l|l|l|l|}
\hline & SS & MD & SA & Physio & Coaches & Athletes \\
\hline SS & ${ }^{*}$ & 1.000 & 1.000 & 1.000 & 1.000 & 0.6073 \\
\hline MD & & ${ }^{*}$ & 1.2869 & 1.000 & 1.000 & 0.7589 \\
\hline SA & & & $*$ & 1.000 & 1.000 & 0.7589 \\
\hline Physios & & & & ${ }^{*}$ & 1.000 & 1.000 \\
\hline Coaches & & & & & ${ }^{*}$ & 0.6562 \\
\hline Athletes & & & & & & $*$ \\
\hline
\end{tabular}

Values in the table are $\mathrm{p}$ values computed lor the Chi-square Test

$\begin{array}{llll}\text { SADM } & \text { - Sports scientists } & \text { MD } & \text { - Medical doctors } \\ \text { SA } & \text { - Sports Administrators } & \text { Physio } & \text { - Physiotherapists }\end{array}$

these visits. Dates were then agreed on when the completed instruments would be retrieved. The importance of this study was highlighted during these meetings. This strategy may have contributed to the successful retrieval of the administered questionnaires.

\section{DATA ANALYSIS}

The data were grouped according to the speciality of the participants and simple percentage evaluations etc used in the analysis.

The Chi-square test was used to determine differences in the responses within and between the various professional groups. The 5\% level was used as the critical level in establishing statistical significance. The computer statistical software, IN-STAT was used to analyse the data.

\section{RESULTS}

A total of one hundred and twenty professionals and athletes were surveyed.

The breakdown of the overall sampled population showed that $3.1 \%$ were sports scientists. Of the participants $23.4 \%$ were medical doctors and $11.7 \%$ sports administrators. Physiotherapists made up $6.3 \%$ of the sample, coaches and athletes $32.8 \%$ and $34.4 \%$ respectively.

When asked about the use of physiotherapy for the treatment of sports injuries by sports physicians $56 \%(72)$ of the sampled population strongly agreed while $40 \%$ (51) agreed, 3\%(4) disagreed and $0.8 \%$ (1) strongly disagreed to the use of physiotherapy for the treatment of injuries by sports physicians (Table 1).

The breakdown of the result showed that $75 \%$ of the sports scientists, $66.7 \%$ of the medical doctors, $20 \%$ of sports administrators, all the physiotherapists, $61.9 \%$ of the coaches, and $50 \%$ of the athletes strongly agreed that physiotherapy services were not optimally utilized by sport physicians. While $25 \%$ of the sports scientists, $33 \%$ of the medical doctors, $80 \%$ of the sports administrators, none of the physiotherapists, $31 \%$ of the coaches and $45 \%$ of the athletes agreed with the opinion that physiotherapy services were also not utilised by sports physicians in the treatment of musculoskeletal injuries. All the professionals surveyed indicated that physiotherapy services were not significantly utilised by the sports physician (Table 4 ).

Table 3 shows that there was no significant utilisation of physiotherapy services by the sports physicians during preparations for multi-sport events in the facilities where the professionals and athletes were located.

Table 5 reveals the common musculoskeletal injuries recorded at the sports medicine centre in a period of four years (1992-1995). The most common injuries were sprains and strains affecting the joints of the upper and lower limbs. Volleyball and athletics (track and field) events recorded the highest referrals of $91 \%$ and $87 \%$ respectively. Football recorded a referral of $74 \%$, while basketball recorded the least of over $56 \%$.

\section{DISCUSSION}

The pattern of the questionnaire allowed two degrees of agreement and two of disagreement for every statement on the use of physiotherapy services by sports physicians for the treatment of sports injuries during training and competitions. It was then possible to evaluate the strength of the responses of each participating professional.

The responses by the professionals surveyed, showed a high level of awareness of the utilisation of physiotherapists in sports. Hence, 123(96\%) of them generally agreed that physiotherapy services were not utilized by sports physicians for the management of musculoskeletal injuries during training for multi-sports 
Table 5. Common musculoskeletal injuries sustained in different elite sports as recorded at the sports medicine center between 1992 - 1995.

\begin{tabular}{|l|l|l|l|l|l|}
\hline \multicolumn{5}{|c|}{ No of injuries and different types of sports } \\
\hline \multicolumn{1}{|c|}{ Types of Injuries } & VB & FB & BB & TF & Part Injured \\
\hline & & & & & \\
\hline Sprain & 7 & 3 & 4 & 25 & Wrist \\
\hline Strain & 11 & 3 & 2 & 23 & Ankle joint, hand, \\
\hline & & & & & Shoulder and knee joints. \\
\hline Dislocation & - & - & 2 & 4 & Shoulder \\
\hline Trauma & - & - & 3 & - & Not specified \\
\hline Contusion & - & - & 4 & 3 & Quadriceps \\
\hline Partial rupture & - & - & 1 & 2 & Rectus femoris \\
\hline Shin splint & - & - & - & 1 & Shin \\
\hline Tendinitis & - & - & - & 3 & Hamstring and \\
\hline Spondylolysthesis & - & - & - & 1 & Spine \\
\hline Spasm & 1 & - & - & 2 & Thigh and \\
\hline Laceration & 1 & - & - & 3 & Hand, head and \\
\hline Bruise & - & - & - & 1 & Fore-arm \\
\hline Back pain & 2 & - & - & 5 & Back \\
\hline Post athroscopy & & & & & \\
\hline Effusion & - & 1 & - & - & Knee \\
\hline Hyper pigmentation & 1 & - & - & - & Hand \\
\hline TOTAL & 22 & 8 & 16 & 73 & \\
\hline CASES REFERRED & 20 & 6 & 9 & 62 & \\
\hline PERCENTAGE & $91 \%$ & $74 \%$ & $56 \%$ & $87 \%$ & \\
\hline VB Volley ball BB Basker & $-61 \%$ \\
\hline
\end{tabular}

VB Volley ball; BB Basket ball; FB Football; TF Track and Field

events. Only $5(4 \%)$ of them disagreed (see Tables 1 and 2). The high level of awareness displayed by the athletes and the professionals must have resulted from their experience and exposure to events of this magnitude in the past. These findings are in agreement with those of Hannay et al, (1993) and Jull and Cupits (1984). Most probably, the low overall response for those who disagreed (disagree (D) and strongly disagree (SD)) on the non-utilisation of physiotherapy services might have come from the few athletes and professionals who were located in states where physiotherapy services are readily available and utilised by sports physicians.

A high percentage of the professionals (except the sports administrators), strongly agreed to the non-utilisation of physiotherapy services by sports physicians during training and preparation for competition.

Twenty-two (50\%) of the athletes strongly agreed and twenty (20) $45 \%$ agreed to non-utilisation of physiotherapy services by sports physicians (Table 1). This represents a total agreement $(\mathrm{SA}+\mathrm{A})$ of $95 \%$. It is however interesting that only $2(5 \%)$ of the athletes generally disagreed $(\mathrm{SD}+\mathrm{D})$ to the non-utilisation of physiotherapy services by sports physicians (Table 2). The athletes who disagreed with the non-utilisation of physiotherapy would probably be those who were based abroad (since they were also invited to these preparatory camps) or located in states where there were established physiotherapy units and therefore had access to these services.

This response should be of great interest to physiotherapists and sports administrators since the care of these athletes is our responsibility. Most of the athletes are usually treated for the first time by physiotherapists when they are invited to national preparatory camps of this nature. The lack of physiotherapy utilisation most likely is one of the factors responsible for athletes with injuries competing at the opening of multisports events. A high rate of pre-existing injury has been reported in the literature (Jelsma et al, 1997a and b; Hannay et al, 1993; Martin et al, 1987; Ahuja and Ghosh, 1985; Jull and Cupit 1984).
The response by the sports administrators, might have been influenced by their perceptions that physiotherapists function as masseurs as they do not comprehend the need for physiotherapy as an essential service during sports training and preparation for competitions. Their perception of the physiotherapist's role agrees with the study of Jull and Cupit (1984) who reported that administrators debated the role of the physiotherapist as a masseur during the XII commonwealth games in Australia.

The response by the sports administrators has serious consequences to the utilisation of physiotherapy services since the administrative decisions on the invitation of physiotherapists to sports preparatory camps rests upon them.

Since the camps were only selection locations for the athletes, they were given the opportunity to reveal the actual utilisation of physiotherapy services available in their respective states or locations. About $62 \%$ of the professionals, athletes and coaches indicated that physiotherapy services were used by sports physicians in their facilities for the management of injuries during training, while $38 \%$ of them held a different opinion. However, the response by all the professionals and athletes was not significant. This high percentage of the utilisation of physiotherapy services observed, agrees with previous studies (Ahuja and Ghosh, 1985, Thompson and Ratcliffe, 1991; Jelsma et al, 1997a and b; Hannay et al, 1993; Martin et al, 1987; Jull and Cupit 1984).

The $62 \%$ response by the groups, only refers to the utilisation but not the degree or extent of such utilisation. Hence, $38 \%$ of non-utilisation of physiotherapy services is quite high. This value may increase if the degree and quality of utilisation of these facilities and services were considered. The absence or lack of full time physiotherapists on the staff of most sports establishments may have also contributed greatly to this high degree of non-utilisation of physiotherapy services by sports physicians during training and preparation for tournaments.

There was no significant difference in response within each of the professional groups and between them on the utili- 
sation of these services (Table 3 and 4). Further studies might be recommended to examine the type and quality of physiotherapy services that are available at these facilities. Also to be considered for further studies is to compare the utilisation of physiotherapy services during preparation for multi-events with the utilisation during competitions.

The percentage referral of musculoskeletal injuries to the physiotherapy department of the sports medicine centre was observed to be high. The high referral agrees with the studies of Jones (1980) and Ahuja and Ghosh (1985), who indicated that many athletes with sports injuries are referred for physiotherapy. However, the high percentage of the referred cases did not agree with the perception of the professionals on the use of physiotherapy by sports physicians. The difference may be attributed to the fact that the professionals were drawn from different parts of the country and that the sporting conditions and physiotherapy services at each of the localities differ from what is obtained at the national sports medical centre.

In addition, due to the inadequate referral system, and poor record keeping, the total number of musculoskeletal injuries recorded at the sports medicine centre may not be a reflection of the total number of injuries that occurred during the four-year period. Another probable reason for a decrease in the number of cases recorded is that some sports like football and basketball keep a full complement of the medical team (of a doctor and physiotherapist) while in preparatory camps. And they would not need to use the services of the physiotherapy unit at the medical centre. Sometimes treatment rendered is not recorded as indicated by Thompson and Ratcliffe, (1991). This may account for the different result obtained from the professional groups and from the records at the medical centre.

It would be appropriate to compare the result of the sports medicine centre with that of other centres within the country. This aspect of the study will be carried out in the near future. However the survey of the sports medicine centre helped to validate the fact that physiotherapy facilities and services were utilised to some extent by sports physicians.

A striking feature of the findings of the distribution and types of injuries was the similarity to those published for multi purpose sports (Jelsma et al, 1997a and b, Jull and Cupit, 1984; Martin et al, 1987). Injuries reported affected both the upper and lower limbs. This is comparable with the studies by Karlsson, (1998) and Fahlstrom et al, (1998). Sprain and strain were also the common types of injuries recorded. These accounted for $78(66 \%)$ of the cases reported.

The sports that recorded the highest referrals after injuries were volleyball and track and field with $91 \%$ and over $87 \%$ respectively. This agrees with the findings of Jelsma et al, (1997b) and Ahuja and Ghosh, (1985).

Basketball and football recorded very few cases of referral because, the elite national football and basketball teams in Nigeria always had their full medical compliment of a physiotherapist and a doctor attached to the team when they were in camp. The need for referral to the medical centre therefore did not arise since the injured athletes could be managed within the camp. It was difficult to collect data from the teams with their own physiotherapist as reported in previous studies (Jelsma et al, 1997a, Jull and Cupit, 1984).

\section{CONCLUSION}

This study revealed under utilisation of physiotherapy services by sports physicians in Nigeria during preparation for multi-sports events. Since sports administrators and doctors make crucial decisions on the general welfare of sports persons and the referral of the injured athletes for physiotherapy services respectively, it may be necessary to educate them on the essential role of the physiotherapist in the management and prevention of injuries in sports. Injuries affecting the joints of the lower limbs were common. Emphasis should therefore be laid on prevention of lower limb injuries especially of the muscles and ligaments during preparatory camps before the actual events.

Also observed was improper documentation of the records at the sports centre. We recommend that a much more comprehensive documentation be included for proper patient auditing. Finally, attempts should be made towards encouraging teams to employ their own physiotherapists since it would go a long way in minimizing preexisting injuries.

\section{REFERENCES}

Ahuja A, Ghosh AK, 1985 Pre-Asiad '82 injuries in elite Indian athletes. British Journal of Sports Medicine 19:24-26.

Allman FL 1974 Sports medicine, 2nd edn.pp308-323.Academic press, New York

Fahlstrom M, Bjornstig U, Lorentzon R, 1998 Acute achilles tendon rupture in badminton player. American journal of Sports Medicine 26:467-70

Jelsma J, Dawson H, Smith G, Satumba C, Madzivire D, 1997 Provision of physiotherapy services at the sixth All African Games. British Journal of Sports Medicine 31:246-248

Jelsma J, Dawson H, Smith G, Masaya T, Madzivire D, 1997 Sports injuries sustained at the sixth all Africa games: the physiotherapy perspective. South African Journal of Physiotherapy 53:17-21.

Jones J, 1980 Cambridge sports injury clinic. Physiotherapy 66: 249-50

Jull GA, Cupit RL, 1984 Physiotherapy at the $\mathrm{X} 11$ Commonwealth games part 1 : organization and utilization of services. The Australian. Journal of Physiotherapy 30:3-4

Hanny DR, English BK,Usherwood TP, Platt M, 1993 The provision and use of medical services during the 1991 world students games in Sheffield. Journal of Public Health Medicine 15:229-234

Karlsson J, 1998 Ligament injuries of the ankle-what happens later? Non-surgical treatment is effective in 80-90 percent of the cases. Lakartidningen 95: 4376-8

Martin RK, Yesalis CE, Foster D, Albright JP, 1987 Sports injuries at the 1985 Junior Olympics: An epidemiologic analysis. The American Journal of Sports Medicine 15: 603-608

Sadat-Ali M, Sankaran-Kutty M, 1985 Sports injuries in Saudi Arabia. British Journal of Sports Medicine 19:28-29

Sperryn PN, 1976 Physiotherapy in sports: reflection from America. Physiotherapy 63: 251-2

Thompson S, Ratcliffe A, 1991 World student games, 1991-Sheffield experience of the student physiotherapist. Physiotherapy 77:820

Watson AWS, 1993 Incidence and nature of sports injuries in Ireland: Analysis of four types of Sport. The American Journal of Sports Medicine. 21:137-143 